\title{
Teaching Emotional Intelligence Online: The Sociology of Discussion Boards
}

\author{
Velda Arnaud \\ Blue Mountain Community College, Pendleton, Oregon \\ Yongsheng Sun \\ Columbia Basin College, Pasco, Washington
}

\begin{abstract}
Author Notes
Velda Arnaud has a long history as a dedicated undergraduate instructor within 2-year, 4year, and career/technical programs. Since 2000, Dr. Arnaud has taught distance learning classes, and she is a strong advocate for open-educational resources to lower students' costs and engage students. Her pillars are leadership, education, and service, and she is committed to helping other people identify their passions.

Yongsheng Sun has been a full-time faculty at Columbia Basin College for over 25 years, and has taught part-time for the graduate program of Teaching and Learning at Washington State University. Dr. Sun has book and journal publications both in the US and abroad. He has also worked as a cultural consultant for the Washington State Board for Community and Technical Colleges, and the Pacific Northwest National Lab operated by Battelle.
\end{abstract}




\begin{abstract}
Student engagement in an online class has always been a challenge to faculty. We all know that online courses can be difficult for some students, and online discussions do not always turn out as planned. How do we maximize our online communication effectiveness? In a case study of an Emotional Intelligence course in a community college setting, we looked at this through a sociological lens and built on the perspective of socialization theories and conceptions to see students quickly become engaged in discussions with their classmates and openly share their concerns. Data was analyzed and lessons learned.

Keywords: online discussion boards, Sociological approach, socialization, Emotional Intelligence, EI
\end{abstract}




\section{Introduction}

Discussion boards are not a new technology. In fact, electronic bulletin boards go back to the 1970s text-based days. Those early text-based bulletin boards were similar to the ones in the hallway where you would post something to the board with a pin. Telnet and Usenet were early bulletin board systems that we remember using. Distance learning also has a long history going back to correspondence courses and tele-courses, which were delivered via television or video tape. These types of distance learning put the onus on the student to read, listen, and comprehend the learning material, and the instructor was in charge of assessment of the learning.

Nowadays, instructors have many things to consider when setting up an online course. For example, they must adhere to Title IV and American Disability Act (ADA) requirements, and their institutions may also need to meet online course standards such as Quality Matters. Title IV requirements are for higher education institutions to be eligible for federal financial aid, so they are important. The two main requirements for Title IV are that the instructor provide regular and substantive interaction (RSI) with students, and the student's last day of attendance must be recorded. RSI must be initiated by the instructor. ADA requirements center on text, images, tables, audio, and video being accessible by everyone, and that requires making sure readability is guaranteed by adding alternate text, providing written transcripts for audio, and including closed-captioning of video. Quality Matters standards relate to the overall design of the course, with guidelines on setting up discussion boards.

We also have robust Learning Management Systems (LMS) that incorporate the ability to deliver multi-media educational content, track attendance, and allow for discussion boards and testing, it is much convenient for an instructor to deliver a course online; however, getting students to engage with the content, each other, and the instructor is often difficult. It is no 
wonder that there is usually at least one session on discussion boards at distance education conferences.

This research presented here was prompted by a discussion at a conference on distance education. The discussion was about the sociology behind students' use of discussion boards. Why are some classes and some students highly engaged whereas others are not? The participants in this research were students enrolled in Emotional Intelligence courses at a community college, and the research was not intended to delve into the emotional intelligence concepts. As the data was analyzed, we saw some patterns and a few surprises.

\section{Literature Review}

As we conducted our research through a sociological lens, there were several different approaches we reviewed. We used Anderson's (2003) framework for learner-learner interaction, learner-content interaction, and instructor-learner interaction. This framework was chosen because 1) this research is focused on student interaction in online discussion boards, and 2) Anderson's framework has strong theoretical base connecting it to Dewey's (1938) "transactional" theory of activity-based education, which has been shown to engage students and improve learning (Anderson, 2003). This literature review will focus on those three areas.

\section{Learner-learner interaction}

Students engaging with each other in a class allows for them to learn from each other and identify how they are similar or dissimilar from their classmates. Engaging with their peers allows students to build communities, and it eliminates the sense of isolation or disconnection that many online students perceive (Keeble, 2017; Aloni \& Harrington, 2018). Providing guidelines, such as netiquette, for communication will facilitate discussions (Asif, Vertejee, \& Lalani, 2015). Introverted students or non-native speakers will have time to formulate their 
thoughts and words for their discussion board posts and responses to their classmates (Delaney, Kummer, \& Singh, 2019; Hall, 2015). Peer-to-peer learning is one of the benefits of using discussion boards (Aloni \& Harrington, 2018).

One way to begin the student-student interaction is to have an "introduce yourself" discussion board the first week of class (Basko \& McCabe, 2018; Bollinger \& Martin, 2018). Including welcome messages and course announcements help set the tone for the course (Bollinger \& Martin, 2018). Building an online community is an important part of creating an environment that allows students to engage with each other, course content, and the instructor (Jan \& Vlachopoulos, 2018). One way to build that community is through sharing personal experiences (Basko \& McCabe, 2018). Required regular discussion boards promote peer discussion as students continue their discussions throughout the course (Delaney, Kummer, \& Singh, 2019).

Research has found that strong online interaction leads to student success. In Bollinger and Martin's (2018) comparison of instructors' and students' perceptions of engagement strategies, both groups identified the introducing yourself activity and collaborative online work as the two most important activities. Likewise, in Cundell and Sheepy's (2018) analysis of survey responses, students rated discussion forums highest. Massive open online course (MOOC) completion rates are very low; however, in their study of MOOCs, Bonafini, Chae, Park, and Jablokow (2017) found that engagement in discussion forums had a $32 \%$ larger impact on completing the MOOC.

Discussion boards for large classes can be difficult to navigate. Research suggests that for large classes, subgroups of about 20 students should be created to encourage discussion (Aloni \& Harrington, 2018; Keeble, 2017; Pilotti, Anderson, Hardy, Murphy, \& Vincent, 2017). These 
subgroups create more manageable cohorts of students and increases, according to the research, student-student interaction.

\section{Learner-content interaction}

The purpose of instruction is for the students to learn, and that requires students to interact with course content. Students must understand the purpose of discussion boards, how those discussions relate to the instruction, and the instructor's expectations; when students are confused, they are less likely to participate (Aloni \& Harrington, 2018). It is important that expectations are set early in the course because students' perceptions need to be aligned with the instructor's expectations at the onset (Delaney, Kummer, \& Singh, 2019). One strategy that can help students understand is by including grading rubrics that clearly indicate discussion post and response expectations (Aloni \& Harrington, 2018; Bollinger \& Martin, 2018; Keeble, 2017).

Well written discussion board prompts will tie in directly with the content being studied, and the discussion prompts will allow the student to explore the topic, think critically, or solve problems. Getting students to participate in depth with discussion boards can be difficult. Students are more likely to participate in discussions when they realize that discussion posts have value, and are being graded. In Delaney, Kummer, and Singh's (2019) research on the impact of online discussion boards, they found a positive relation between discussion board participation and grades, and they found that incentives motivate students to participate. Based on their literature review, Aloni and Harrington (2018) suggested a discussion board weight of between $10 \%$ and $20 \%$ of the final grade - the weight must be enough to motivate students. On the other hand, Keeble (2017) encourages a higher weighting of 20\%-30\%.

Each student comes into a course with knowledge and skills from previous experiences (Henrikson, 2019). Those students who are more self-directed will likely have a higher level of 
engagement in the discussion posts (Asif, Vertejee, \& Lalani, 2015; Henrikson, 2019; Jan \& Vlachopoulos, 2018). An active student-to-student engagement would be where students are discussing the content while offering each other support or encouragement (Johnson, et al., 2017).

In their research of 303 online asynchronous courses, Pilotti, Anderson, Hardy, Murphy, and Vincent (2017) found that when students are emotionally engaged with a course, they post more self-reflective statements (I, we, etc.), write longer posts, and receive better grades. For these reasons, creating discussion post prompts that allow for deeper learning of the course content through learner-learner interaction should be a priority (Cundell \& Sheepy, 2018).

\section{Instructor-learner interaction}

Pilotti, Anderson, Hardy, Murphy, and Vincent (2017) found a positive connection between students' willingness to learn in the classroom and the instructors' displayed behaviors in the course. Students will not participate in discussion boards if they feel they are not valued or connected - instructors should comment consistently with each student (Aloni \& Harrington, 2018). On the other hand, instructors should not dominate discussions, stifle student voices, or discourage critical thinking (Aloni \& Harrington, 2018; Hall, 2015). The discussion forum should be a student-centered environment where students own the discussion (Hall, 2015). It is important that the instructor determine, well before class begins, on his or her role in the discussion boards and communicate that to the students.

Instructor "presence" in an online course is difficult to define because different subject matters call for more or less involvement. That said, instructors should not be overly involved, either (Aloni \& Harrington, 2018). Basko and McCabe (2018) found that students prefer timely feedback and grading to build trust, and that even though $52 \%$ of an online instructor's time is 
spent on grading and monitoring discussions, the instructor's presence is important. Cundell and Sheepy (2018) viewed much of this "presence" to be administrative with the instructor configuring the discussion prompts and remaining outside the actual discussion. Indeed, the configuration of each discussion prompt requires effort to connect the subject matter, the student, and the concepts to be learned.

The instructor creates the online environment. The design of the course can help motivate the students to become engaged (Johnson, et al., 2017). Henrikson (2019) found that the instructor created the "continuum of experience" with the course design (p. 29). How the course is structured, the colors, links, technological tools, and content represent the instructor. Each instructor should make an effort to be genuine, which builds trust (Aloni \& Harrington, 2018; Basko \& McCabe, 2018; Cundell \& Sheepy, 2018; Evans, Steele, Robertson, \& Dyer, 2017). Sharing "learn from my mistakes" can be a teachable moment (Basko \& McCabe, 2018, p. 122).

Feedback should not only be timely, but, if possible, it should be personalized for each student (Asif, Vertejee, \& Lalani, 2015; Basko \& McCabe, 2018; Larson, Aroz, \& Nordin, 2019). In Bollinger and Martin's (2018) research on engagement strategies and student perceptions, students rated faculty members using their names highly (89.4\%). Using different formats (audio, video, and text) for discussion post responses and instructor's feedback can be more engaging for everyone (Johnson, et al., 2017; Henrikson, 2019).

In Bollinger and Martin's (2018) research of engagement strategies, the students rated course announcements and email reminders as the top (96.9\%) instructor-student engagement strategy. In Aloni and Harrington's (2018) literature of asynchronous discussion boards, they suggested that the instructor could do more than give a weekly summary by mentioning themes, highlighting important information, or correcting common misconceptions, and thus building the 
online learning community.

Having well-structured discussion posts is important for students and instructors alike (Aloni \& Harrington, 2018; Bollinger \& Martin, 2018; Hall, 2015). Too many discussion threads can be overwhelming to follow, and students may suffer from information overload (Aloni \& Harrington, 2018). Research studies have emphasized the need to carefully craft discussion prompts to be specific; be open-ended; use Bloom's highest level verbs for crucial thinking: analyze, synthesize, and evaluate; and allow for broad answers and deep thinking (Aloni \& Harrington, 2018; Bonafini, Chae, Park, \& Jablokow, 2017; Cundell \& Sheepy, 2018; Hall, 2015).

\section{Theoretical Perspectives}

It is important and useful to formulate our study through a sociological lens. Sociological conceptions and understandings of the theory of microsociology, the compulsion of proximity, and socialization factors provided the framework to guide this study.

\section{Microsociology}

As we know, Sociology is the scientific study of humans in relation to the society (Sun, 2020). Microsociology is the study of everyday human life behaviors and face-to-face social interactions of individuals and small groups (Giddens et al., 2019; Jacobs and Townsley, 2020). The concept of Microsociology was first coined in the 1950s by the sociologist Harold Garfinkel, who described this term in his study which focused on individual interactions and communications (Garfinkel, 1963). Microsociology can help us better understand human behaviors and small group interactions, and therefore better design our online discussion boards. Sociologist Erving Goffman, whose study focused on social interactions and socialization, also addressed the concept of Microsociology. Goffman (1963) believed it was important to study the 
seemingly insignificant small things in human interactions and socialization because they allow us to have a better understanding of human behaviors and thus give us opportunities to act creatively in shaping our environment (Goffman, 1973; Giddens et al., 2019). The framework of Microsociology, human interactions and socialization, which focus on the little things, the mundane things people do and have in daily life, such as daily conversations, helped us conduct this study and understand the sociology of online discussion boards.

\section{Compulsion of Proximity}

Today, we live in a global village and are interconnected and interdependent like never before (Sun, 2009). We have internet, email, social media, and more and more people are interacting online rather than face-to-face (Madden et al., 2013; Sun 2020). Would social media and the electronic communication replace human face-to-face interactions? In their study, Sociologists Deirdre Boden and Harvey Molotch asked how far can electronic communication substitute for face-to-face interaction, and the concept of compulsion of proximity came into being. The compulsion of proximity is the argument that humans have a true natural need for personal interactions in their presence (Giddens et al., 2019; Ferris \& Stein, 2020). Humans need to socialize and interact in order to live happily, efficiently, and it is in people's well-being to share ideas and connect with each other (Sun, 2020). Boden and Molotch concluded in their study that there is really no substitute for human face-to-face interactions.

\section{Socialization Factors}

It is not uncommon to find people who tend to dominate, and people who get dominated and even become marginalized in our daily face-to-face interactions and socialization. People who are marginalized tend to feel disconnected and isolated, or even become fearful to socialize. In a face-to-face setting, sometimes we can see who is dominating and who is marginalized in 
the class, and we can intervene accordingly to ensure inclusive student engagement and smooth student participation in the classroom. But that is harder to do in an online class setting and modality since we do not see students in action and cannot tell as easily as we could in a face-toface setting. In fact, COVID-19 has made people especially more stressed out and isolated than before. There is now a so-called COVID syndrome that has nothing to do with the virus itself, but everything to do with its negative impact on human emotional, mental, and psychological well beings. So, with that sociological understanding, how do we better promote student engagement in online classes? One answer is through the use of discussion.

When we investigate using discussion boards to remedy online student isolation and disconnect, there are quite a few advantages of discussion boards in online classes, especially in dealing with the fear of socialization and possible isolation. Some of the most prominent examples are:

- People can focus purely just on the content of the message and not get distracted as in a face-to-face setting.

- People who are shy or not as confident may become empowered and liberated and speak more freely behind the computer screen than they would otherwise. The less confident group would include people who are from traditionally disadvantaged groups, such as women, and marginalized groups, such as ESL students, and introverts.

- Discussion boards actually may forge or enhance stronger social interaction and integration since people communicate purely upon each other's views and common interest, and that builds better engagement, better trust, and better relationships. These are especially true in the middle of this COVID-19 pandemic. 
Therefore, when we put everything together with online discussion boards, student socialization, and behaviors, we can understand through the Symbolic Interactionist Approach which focuses on small groups of people, and on little things that humans are social creatures and social interaction is just part of our everyday life. We humans have a true natural need for social interactions. People may feel a sense of emptiness or even despair if not having been heard by or having listened to somebody else (Sun, 2020). The symbolic interactionist approach was developed by early sociologist George Herbert Mead. This is a theoretical approach that emphasizes on the role of language and symbols in analyzing the social world. Mead argued that all human interactions involve an exchange of symbols, and a complex and subtle process of symbolic interpretation shapes our interactions (Giddens et al., 2019; Ferris \& Stein, 2020). Through this interpretation, we see ourselves as others see us. According to the symbolic interactionist approach, social life is constructed through the interactions of individuals, and those interactions gain meaning and reflect back to shape the behaviors of the individuals in our everyday life (Blumer, 1968; Glass, 2009). We gain perspectives and adjust our behaviors and mentality based on our socialization and interactions with others (Sun, 2020). Having that understanding is vital in our efforts to provide adequate opportunities for students to interact and socialize in our online classes with the use of discussion boards.

As educators, our understanding of Emotional Intelligence helps us improve our online teaching and maximize our online communication effectiveness. Understanding of Emotional Intelligence helps us better serve our students in teaching and learning as people better regulate and manage their emotions and appreciate other people's points of views in their participation of the discussion board activities. Likewise, as students better understand and manage their own emotions, they tend to connect with others better, have more empathy, and be more positive 
which all lead to better engagement in the discussions and the classes. Discussion boards allow students to remain in the back stage instead of risking the possibility of ruining their expected or preferred personal image in the front stage, which takes away their possible nervousness and uneasiness (Sun, 2020). That, therefore, makes personal impression management a lot easier. Students have time to think and compose first, and then respond in a later time of their choice in discussion boards. The much-aligned and well-designed discussion boards can help people avoid the detrimental effects of social isolation and possible social intimidation when taking online classes during this COVID-19 pandemic.

In a nutshell, by using the symbolic interactionist theory, we can see students getting into a new form of interaction through discussion boards, getting influenced by their classmates and peers, attaching meanings and values to the substance and behaviors of each other, and reshaping their own behaviors and images in the process. By participating in this new form of social interaction, instead of face-to-face, students create and make meaning in their interactions and get a sense of belonging, affiliation, and even personal identification in the process. The feedback and interpretations students receive from their peers in the discussions come around to reinforce, shape, and enhance their own self-awareness, self-consciousness, and self-esteem (Sun, 2020). Students, therefore, will feel more willing and more interested in engaging in online discussions that are well-designed with emotional intelligence considerations. It was mentioned earlier that if students can understand and manage their own emotions better, they will connect with others better, and they will be more positive engaging in the discussions and the classes overall. And that is exactly what we, as educators, want because it is all about increasing student engagement and understanding in our online settings. 


\section{Methods}

This study is set in a Sociological understanding and we examined discussion boards in 6 Emotional Intelligence courses over 4 years. The first 3 courses were hybrid in which students met face-to-face or via Zoom on weeks 1, 5, and 10. The discussion prompts that were analyzed were the same throughout all 6 courses. Overall, there were 93 students, with the average class size being 16 students per term. Looking at only three weeks each time, there were a total of 840 discussion posts analyzed.

We used the Threadz LTI that was developed by Eastern Washington University to visualize student interactions in Canvas. Threadz provides data about the number of interactions, post word counts, discussion thread word counts, and averages. The graphics generated by Threadz visually show behaviors that seem to signal isolation, interaction, and integration. Finally, a qualitative analysis of the words used to respond to classmates' posts was performed.

\section{Discussions}

While reviewing the discussion posts in six emotional intelligence courses, we were able to visually see students' behaviors as you will see in the figures from the Threadz program. Throughout the term, students shared more in-depth and personal information, and they were encouraging and supportive of their classmates.

Figure 1 illustrates an example discussion thread and how the students interacted. The dark blue indicates the person who initiated the discussion thread. The light blue are responses. The size of the circle indicates the length of the thread. On the top right side of Figure 1 there is a lone circle for $\mathrm{CM}$. The lone circle indicates no comments from other students, which is an isolated initial post. On the bottom left of Figure 1, there are responses to the initial prompt, but not much discussions. Near the middle are responses to comments, and the original person, AR, 
responds to MY's comment. Figure 2 shows a chord view of the same discussion.

\section{Figure 1}

Winter 2018 week 6 discussion, post, reply, and length

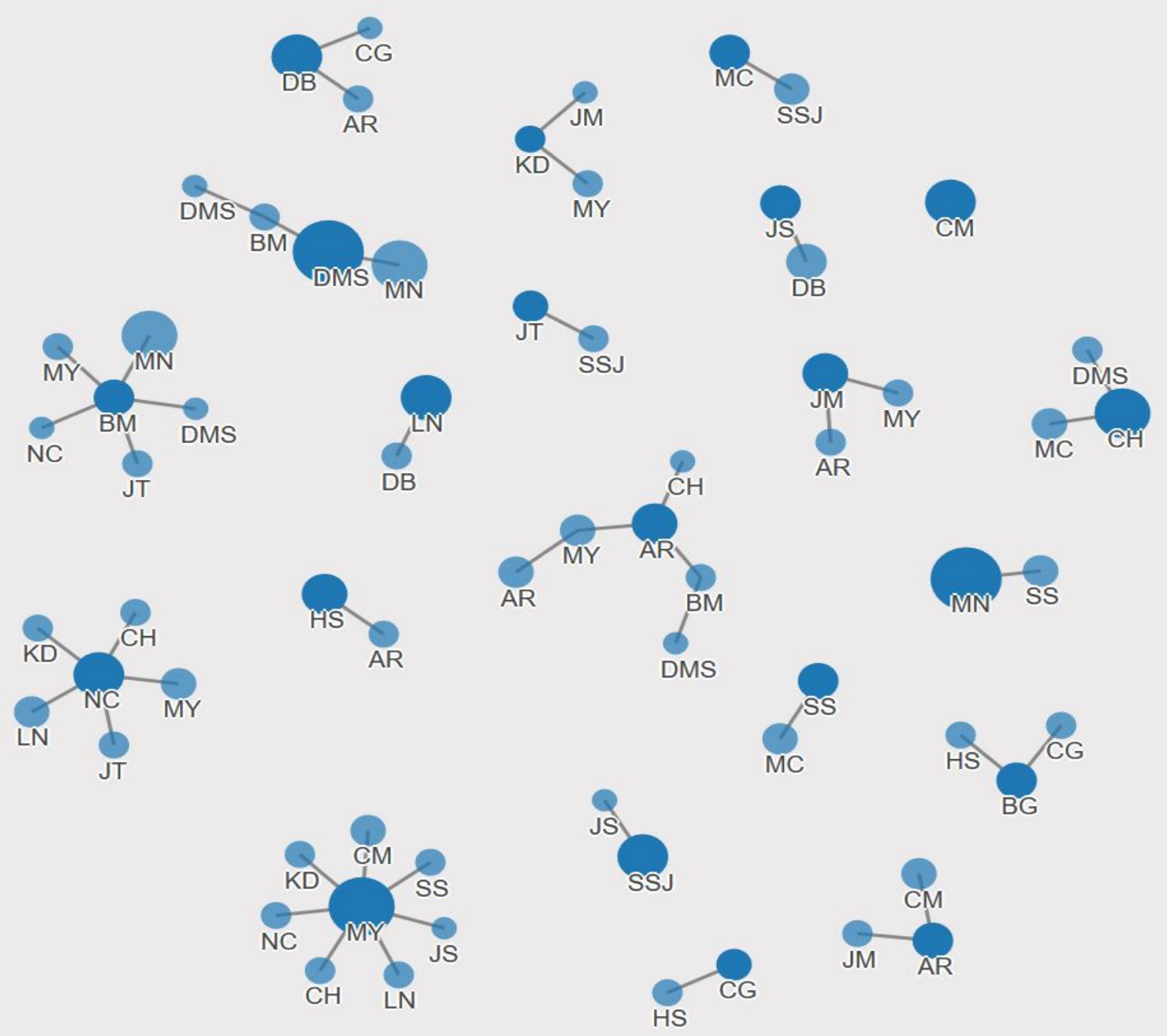




\section{Figure 2.}

Winter 2018 week 6 discussion chord view

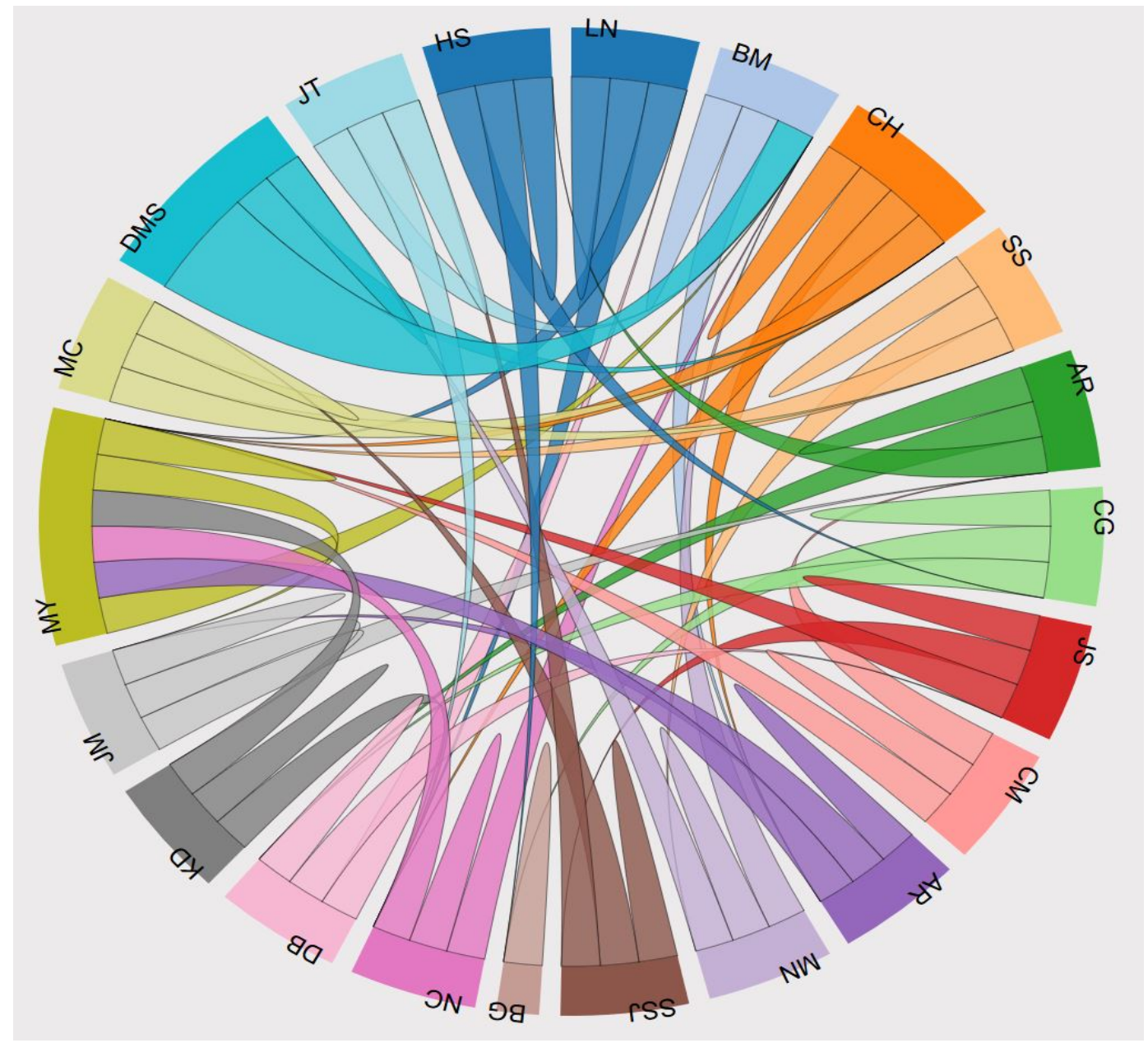

We had some expectations as we began to analyze the discussion board. These were based on our experiences teaching online courses:

- Students would write more as the term progressed. For example, new students do not always understand course expectations or grading rubrics.

- Interactions between the students would increase as students progressed throughout the term, i.e., more comments on their classmates' posts.

- By the end of the term, students would be meeting the grading rubric expectations by responding to their classmates' posts. 
- There would be some engagement differences between the hybrid (first 3) and online courses with the hybrid courses having more student engagement.

However, as shown in the column chart in Figure 3 Average student word count, the average student word count rose by week 6, and then, with the exception of summer 2020 during COVID, the word count declined. It is possible that summer 2020 declined from the onset because of the stress and frustration of the social restrictions.

\section{Figure 3}

Average student word count

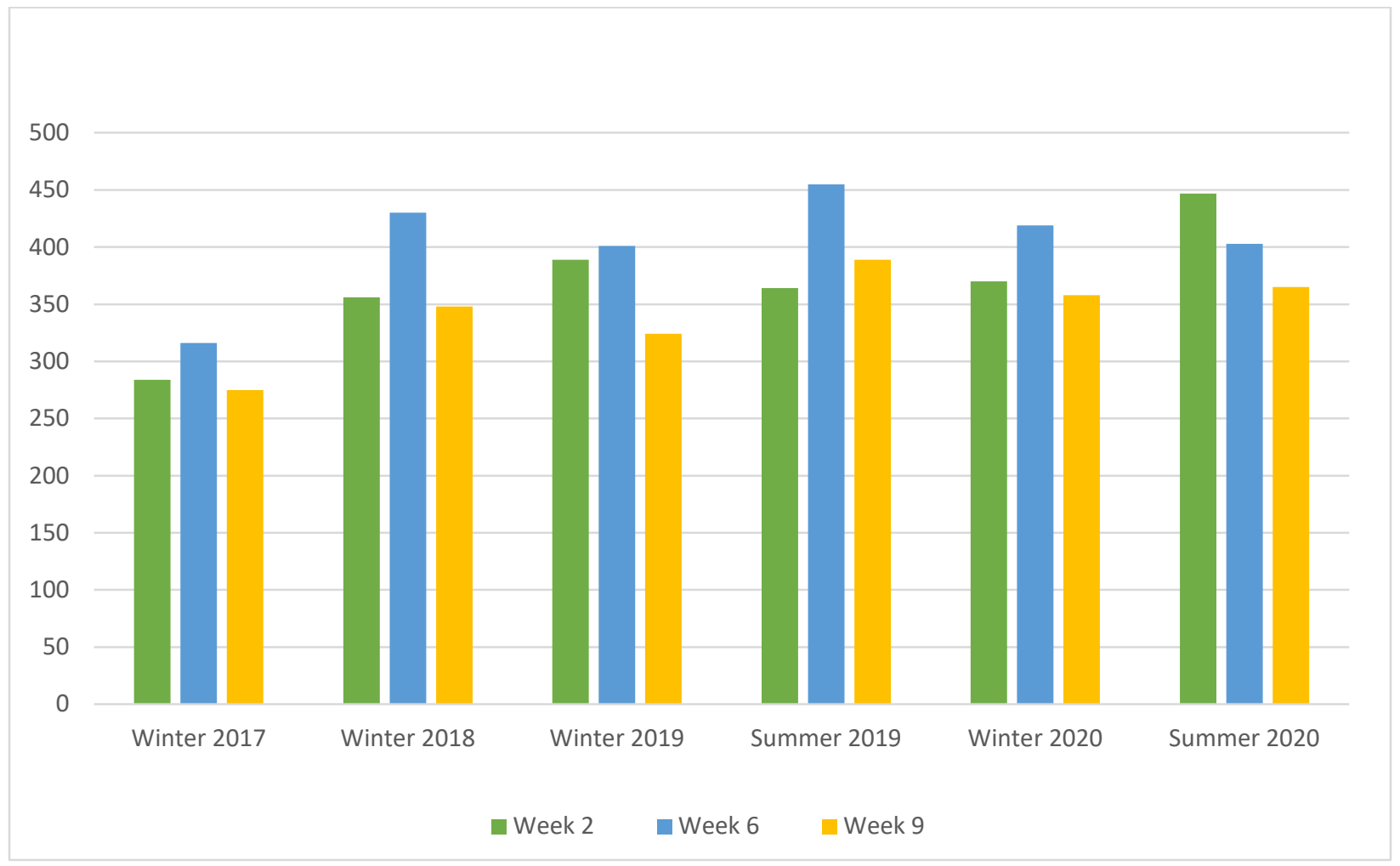

We are unsure about why the word count declined towards the end of the term; however, the number of replies also decreased, as is shown in Figure 4. It is likely that the increased stress of finals and end-of-the-term pressures resulted in briefer and fewer discussion postings.

In the column chart in Figure 4 Average number of replies per student, we see that 
students were meeting the required number of replies per post, which was 2 , at the beginning of the term. Students did not exceed the course requirements.

\section{Figure 4}

Average number of replies per student

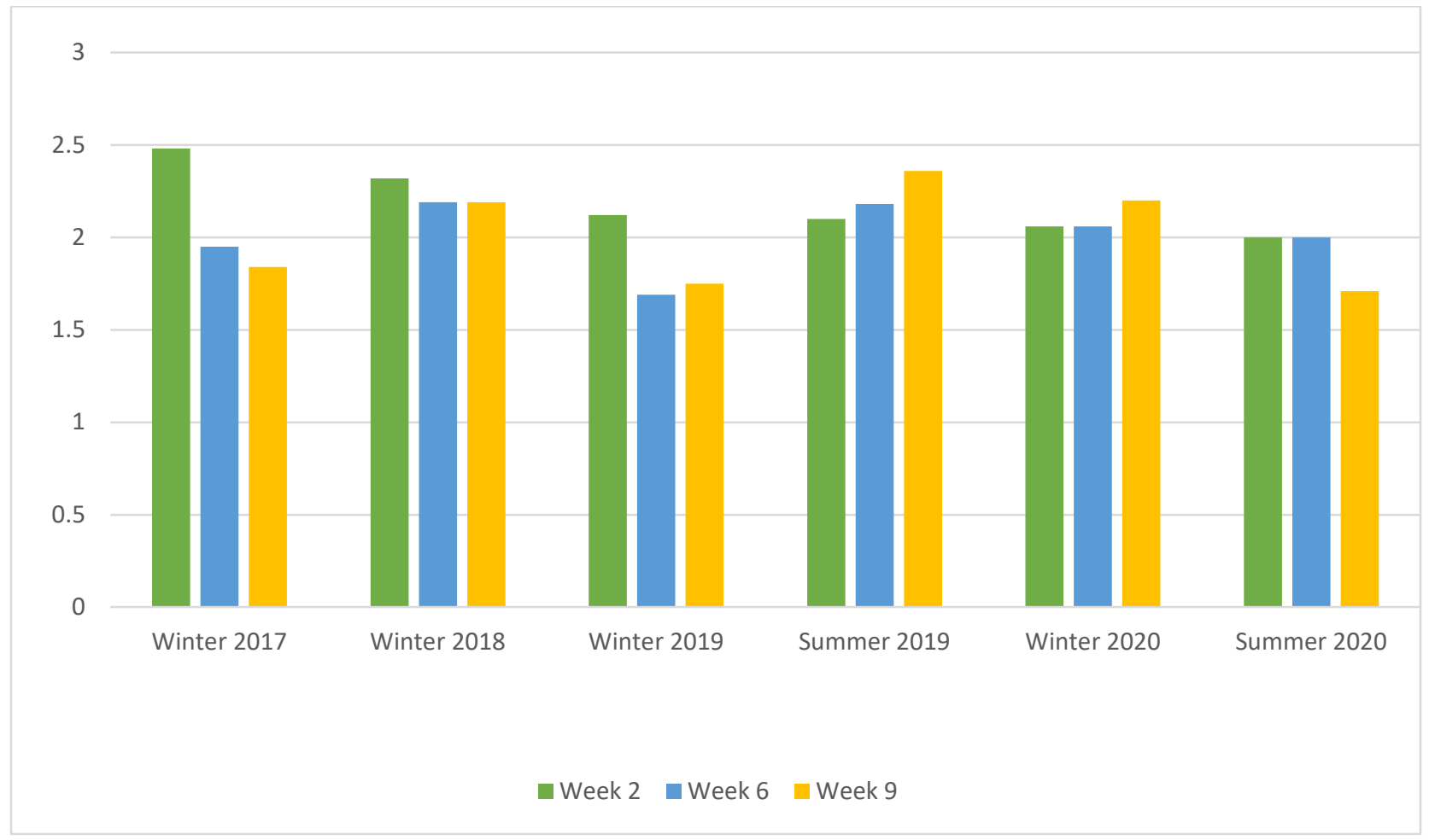

In the qualitative analysis of discussion post responses, we found quite a few phrases that kept coming up. Those common phrases as well as some unique, supporting phrases are listed in the two columns of Figure 5. 


\section{Figure 5}

\section{Common student discussion board comments}

Common student phrases

- I agree with you

- You did a great job

- I would do the same thing

- I can relate|

- I completely understand

- No kidding!!!

- I love that...

- It makes me happy...
Unique, supportive phrases

- I was deeply touched

- I'm glad you shared this story

- I'm sorry for your loss

- I hope things continue to improve

- The honesty in your post is amazing

- Keep the good vibes up

- This response made me "aww"!

Finally, here are some end-of-the-term feedback comments from the students that tell us that discussion boards are important to helping students build connections with each other and the course content:

- "In this course I came in skeptical. Which I believe helped me because it allowed me to think more objectively, and helped me try on all sides rather than my opinion. I learned a lot in this class. Learned a lot about the other people in the class through the discussions."

- "Another important thing I have learned is how to take time and try and understand a person to get to the real meanings of what they say and what they truly mean without judging them first."

- "This class has also taught me that even if we are all different, everyone goes through similar situations. Whenever we had a discussion, I found myself amazed at how 
similar my classmates thought."

\section{Findings}

Through both our quantitative and qualitative analyses, we arrived at three findings:

1. There was no difference between the student engagement with their discussion postings in the hybrid and online courses in this study.

2. Students were in general supportive and encouraging of each other with their comments. Student often provided personal and professional experiences in initial posts and responses (some were even very detailed).

3. For the most part, students used positive wording in their responses to the discussion prompt. In both their posts and responses, students were very honest and open.

4. While students support of their classmates was evident, their word counts and number of posts decreased by the end of the term.

\section{Conclusions}

In order to maximize our online communication effectiveness, we learned that we need to engage students more, and educators should remember the socialization factors when creating online discussion boards. It is also important that we encourage student participation in discussion board by giving them credit for it. We also need to make sure the discussion topics are closely tied to the content of the class so that students see and understand the value of the activity. It is important to encourage and scaffold deeper thinking and problem solving. To ensure student discussions be more directed and orderly, instructors may guide the discussion threads better if they post the discussion prompt and provide clear guidelines on students' postings. For example, instructors set the parameters, share grading rubrics, set appropriate 
deadlines for both original response and later peer responses It is important to establish our involvement with the student discussions. If an instructor wants to be involved in the classroom discussions, become involved right away online. If you are more hands-off with your smallgroup discussions, let your students know. Make sure you give every student feedback each week. We like to praise those students who are doing a great job to move the discussion forward, while pushing those students who are lagging. We can always set up a watercooler for random conversations, and set up individual team or group discussions.

It is important to establish criteria in online discussions. We use a standard rubric so that grading remains the same throughout the course. For instance, we set a minimum for the response to the discussion prompt of two paragraphs and for the responses to the classmates to be four sentences that move the discussion forward. We may also require students to reply to all questions they are asked. We put the criteria in the syllabus and on the first, and sometimes second, discussion prompt. We also have interesting prompts since we want students to have fun with them, and we want to enjoy reading them. We provide variety of media content such as pod casts, YouTube videos, Ted Talks, etc.

Students who posted earlier have more replies than students who posted near the deadline. We found that if students know each other, even if only virtually, they are more engaged at the onset. Generally, students meet the discussion requirements. Discussion boards allow students to feel included. Shy students have time to think before writing. English as a Second Language (ESL) speakers have more time to word-smith their posts and replies. One thing to keep in mind is that interaction is not engagement. There is more than topic and modality that determines how students engage. For instance, students' previous experience with discussion boards and familiarity with instructor's expectations. 
While we expected there to be a difference between student engagement in discussion boards in online and hybrid courses, we found no significant differences. We also expected students to write more as the weeks progressed, and for their student-student interactions to increase over the course of the term. While we did not find an increase in writing or the number of interactions, we did find that students were supportive and encouraging of each other, and they used positive wording and shared personal experiences, all of which are critical in building a health learning community that is essential in student success. 


\section{References}

Aloni, M., \& Harrington, C. (2018). Research based practices for improving the effectiveness of asynchronous online discussion boards. Scholarship of Teaching and Learning in Psychology, 4(4), 271-289.

Anderson, T. (2003). Modes of interaction in distance education: Recent developments and research questions. In M. G. Moore \& W. G. Anderson (Eds.), Handbook of distance education (pp. 129-144). Mahwah, NJ: Erlbaum.

Asif, N., Vertejee, S., \& Lalani, S. (2015). Interaction and cognitive engagement in online discussions in professional development leadership and management course at a private nursing institution. Journal of Education and Training Studies, 3(6), 271-278. doi:10.11114/jets.v3i6.1024

Basko, L., \& McCabe, C. (2018). Keeping your sanity while keeping your students: How teacher engagement can increase student persistence when teaching students during their first college course. Journal of Instructional Research, 7, 119-123.

Blumer, H. (1968). Symbolic interactionism: Perspective and method. Berkley, CA: University of California Press.

Bollinger, D. A., \& Martin, F. (2018). Instructor and student perceptions of online student engagement strategies. Distance Education, 39(4), 568-583.

doi:10.1080/01587919.2018.1520041

Bonafini, F. C., Chae, C., Park, E., \& Jablokow, K. W. (2017). How much does student engagement with videos and forums in a MOOC affect their achievement? Online Learning, 21(4), 223=240. doi:10.24059/olj.v21i4.1270

Cundell, A., \& Sheepy, E. (2018). Student perceptions of the most effective and engaging online 
learning activities in a blended graduate seminar. Online Learning, 22(3), 87-102.

doi:10.24059/olj.v22i3.1467

Delaney, D., Kummer, T.-F., \& Singh, K. (2019). Evaluating the impact of online discussion boards on student engagement with group work. British Jounal of Educaiton Technology, 50(2), 902=920. doi:10.1111/bjet.12614

Dewey, J. (1938). Experience and education. New York: Simon and Schuster.

Evans, S., Steele, J., Robertson, S., \& Dyer, T. (2017). Personalizing post titles in the online classroom: A best practice? Journal of Educators Online, 14(2), 46-54.

Ferris, K.\& Stein, J. (2020). The real world: An introduction to Sociology. (7th ed.). New York, NY: W.W. Norton and company.

Garfinkel, H. (1963). A conception of, and experiments with, "trust" as a condition of stable concerted actions. In O. J. Harvey (Ed.), Motivation and Social Interaction. New York, NY: Ronald Press.

Giddens, A., Duneier, M, Appelbaum, R. P., and Carr, D. (2019). Essentials of Sociology. (7th ed.). New York: W.W. Norton and Company.

Glass, J. (2009). Clinical Sociology. In J. Price, R. A. Straus, and J.R. Breese (Eds.), Doing Sociology.

Goffman, E. (1973). The presentation of self in everyday life. New York, NY: Overlook Press.

Hall, R. A. (2015). Critical thinking in online discussion boards: transforming an anomaly. The Delta Kappa Gamma Bulletin, 21-27.

Henrikson, R. (2019). Using online lectures to promote engagement: Recognising the selfdirected learner as critical for practical inquiry. 23(1), 17-32.

Jacobs, R \& Townsley, E. (2020). Living sociologically. New York: Oxford University Press. 
Lanham, Maryland: Lexington Books.

Jan, S. K., \& Vlachopoulos, P. (2018). Influence of learning design of the formation of online communities of learning. International Review of Research in Open and Distributed Learning, 19(4), 1-16.

Johnson, C., Hill, L., Lock, J., Altowairiki, N., Ostrowski, C., da Rosa dos Santos, L., \& Liu, Y. (2017). Using design-based research to develop meaningful online discussions in undergraduate field experience courses. International Review of Research in Open and Distributed Learning, 18(6), 36-53.

Keeble, P. G. (2017, August). Assessing online asynchronous communication strategies designed to enhance large student cohort engagement and foster a community of learning. Journal of Education and Training Studies, 5(8), 92-100. doi:10.11114/jets.v5i8.2539

Larson, E., Aroz, J., \& Nordin, E. (2019). The Goldilocks paradox: The need for instructor presence but not too much in an online discussion forum. Journal of Instructional Research, 8(2), 22-33.

Madden, M., Lenhart, A., Cortesi, S., Gasser, U., Duggan, M., Smith, A. and Beaton, M. (2013). Teens, social media, and privacy. Pew Research Center. Retrieved from https://www.pewresearch.org/internet/wpcontent/uploads/sites/9/2013/05/PIP_TeensSoci alMediaandPrivacy_PDF.pdf

Pilotti, M., Anderson, S., Hardy, P., Murphy, P., \& Vincent, P. (2017). Factors related to cognitive, emotional, and behavioral engagement in the online asynchronous classroom. International Journal of Teaching and Learning in Higher Education, 29(1), 145-153. Sun, Y. (2009). Global Education: A Case Study. Saarbrucken: LAP LAMBERT Academic Publishing. 
Sun, Y. (2020). Social Life and Privacy in the Age of the Internet - A sociological Perspective. Journal of Strategic Innovation and Sustainability, 15(7). doi:10.33423/jsis.v15i17 